\title{
Retrospective study of prognostic factors in pediatric invasive pneumococcal disease
}

\author{
Nan-Chang Chiu 1,2,3 , Hsin Chi ${ }^{1,2,3}$, Chun-Chih Peng 1,2,3 , Hung-Yang Chang ${ }^{1,4}$, Daniel Tsung-Ning Huang ${ }^{1,2}$, \\ Lung Chang ${ }^{1,2}$, Wei-Te Lei ${ }^{5}$, Chien-Yu Lin ${ }^{\text {Corresp. } 5}$ \\ 1 Pediatrics, MacKay Children's Hospital, Taipei, Taiwan \\ 2 MacKay Junior College of Medicine, Nursing and Management, Taipei, Taiwan \\ 3 MacKay Medical College, New Taipei, Taiwan \\ 4 Department of Medical Technology, Jen-Teh Junior college of Medicine, Nursing and Management, Miaoli, Taiwan \\ 5 Hsinchu MacKay Memorial Hospital, Hsinchu, Taiwan \\ Corresponding Author: Chien-Yu Lin \\ Email address: mmhped.lin@gmail.com
}

Streptococcus pneumoniae remains the leading causative pathogen in pediatric pneumonia and bacteremia throughout the world. The invasive pneumococcal disease (IPD) is known as isolation of $S$. pneumoniae from a normally sterile site (eg, blood, cerebrospinal fluid, synovial fluid, pericardial fluid, pleural fluid, or peritoneal fluid). The aim of this study is to survey the clinical manifestations and laboratory results of IPD and identify the prognostic factors of mortality. From January 2001 to December 2006, a retrospective review of chart was performed in a teaching hospital in Taipei. The hospitalized pediatric patients with the diagnosis of pneumonia, arthritis, infectious endocarditis, meningitis or sepsis were recruited. Among them, 50 patients were pneumococcal infections proved by positive culture results or antigen tests. Clinical manifestations, laboratory data and hospitalization courses were analyzed. The median age was 3.5-year-old and there were 30 male patients (60\%). Eight patients (16\%) had underlying disease such as leukemia or congenital heart disease. Hemolytic uremic syndrome (HUS) was observed in ten patients and extracorporeal membrane oxygenation (ECMO) was performed in three patients. Leukocytosis, elevated C-reactive protein and AST level were noted in most of the patients. The overall mortality rate was $10 \%$. We found that leukopenia, thrombocytopenia and high CRP level were significant predictors for mortality. In conclusion, S. pneumoniae remains an important health threat worldwide and IPD is life-threatening with high mortality rate. We found leukopenia, thrombocytopenia, and high CRP levels to be associated with mortality in pediatric IPD, and these factors are worthy of special attention at admission. Although we failed to identify a statistically significant prognostic factor in multivariate analysis due to relatively small sample size, we suggest an aggressive antibiotic treatment in patients with these factors at admission. 
Further large-scale studies are warranted. 


\section{Retrospective study of prognostic factors in pediatric invasive}

\section{2 pneumococcal disease}

3 Nan-Chang $\mathrm{Chiu}^{1,2,3}$, Hsin Chi ${ }^{1,2,3}$, Chun-Chih Peng ${ }^{1,2,3}$, Hung-Yang Chang ${ }^{1,4}$,

4 Daniel Tsung-Ning Huang ${ }^{1,2}$, Lung Chang ${ }^{1,2}$, Wei-Te Lei ${ }^{5}$ and Chien-Yu Lin ${ }^{5}$

$5 \quad{ }^{1}$ Department of Pediatrics, MacKay Children's Hospital, Taipei

$6 \quad{ }^{2}$ MacKay Junior College of Medicine, Nursing and Management, Taipei

$7 \quad{ }^{3}$ MacKay Medical College, New Taipei

$8{ }^{4}$ Department of Medical Technology, Jen-Teh Junior college of Medicine, Nursing

9 and Management, Miaoli

$10 \quad{ }^{5}$ Department of Pediatrics, Hsinchu MacKay Memorial Hospital , Hsinchu City

12 Correspondence: Dr. Chien-Yu Lin, Hsinchu MacKay Memorial Hospital, Hsinchu

13 city. No.690, Sec. 2, Guangfu Rd, East Dist, Hsinchu City 30071, Taiwan (e-mail:

14 mmhped.lin@gmail.com)

15 Nan-Chang Chiu and Hsin Chi contribute to this work equally. 
18 Abbreviations: AST $=$ aspartate aminotransferase, $\mathrm{CRP}=\mathrm{C}$-reactive protein, $\mathrm{CSF}$

19 = cerebrospinal fluid, $\mathrm{ECMO}=$ extracorporeal membrane oxygenation, $\mathrm{HUS}=$

20 hemolytic uremic syndrome, IPD = invasive pneumococcal disease, $\mathrm{MIC}=$

21 minimal inhibitory concentration, $\mathrm{PD}-1=$ programmed cell death 1 protein, $\mathrm{T}-\mathrm{Ag}=$

22 Thomsen-Friedenreich antigen. 


\section{Abstract}

28 Streptococcus pneumoniae remains the leading causative pathogen in pediatric pneumonia and

29 bacteremia throughout the world. The invasive pneumococcal disease (IPD) is known as

30 isolation of $S$. pneumoniae from a normally sterile site (eg, blood, cerebrospinal fluid, synovial

31 fluid, pericardial fluid, pleural fluid, or peritoneal fluid). The aim of this study is to survey the

32 clinical manifestations and laboratory results of IPD and identify the prognostic factors of

33 mortality. From January 2001 to December 2006, a retrospective review of chart was performed

34 in a teaching hospital in Taipei. The hospitalized pediatric patients with the diagnosis of

35 pneumonia, arthritis, infectious endocarditis, meningitis or sepsis were recruited. Among them,

3650 patients were pneumococcal infections proved by positive culture results or antigen tests.

37 Clinical manifestations, laboratory data and hospitalization courses were analyzed. The median

38 age was 3.5-year-old and there were 30 male patients $(60 \%)$. Eight patients $(16 \%)$ had

39 underlying disease such as leukemia or congenital heart disease. Hemolytic uremic syndrome

40 (HUS) was observed in ten patients and extracorporeal membrane oxygenation (ECMO) was

41 performed in three patients. Leukocytosis, elevated C-reactive protein and AST level were noted

42 in most of the patients. The overall mortality rate was $10 \%$. We found that leukopenia,

43 thrombocytopenia and high CRP level were significant predictors for mortality, although they

44 are not statistically significant is multivariate analysis. In conclusion, $S$. pneumoniae remains an

45 important health threat worldwide and IPD is life-threatening with high mortality rate. We found

46 leukopenia, thrombocytopenia, and high CRP levels to be associated with mortality in pediatric

47 IPD, and these factors are worthy of special attention at admission. Although we failed to

48 identify a statistically significant prognostic factor in multivariate analysis due to relatively small

49 sample size, we suggest an aggressive antibiotic treatment in patients with these factors at 
50 admission. Further large-scale studies are warranted.

51

52

53 


\section{INTRODUCTION}

Streptococcus pneumoniae, a Gram-positive diplococcus, remains the leading causative pathogen in pediatric pneumonia and bacteremia worldwide.(Jroundi et al. 2014; Tan 2012) Colonization with $S$. pneumoniae is common and contributes to invasive disease.(Hamaluba et al. 2015) In 2000, S. pneumoniae reportedly caused 14.5 million episodes of serious disease and $11 \%$ of all deaths in children younger than 5 years.(O'Brien et al. 2009) Invasive pneumococcal disease

61 (IPD) is defined as isolation of $S$. pneumoniae from a normally sterile site (e.g., blood,

62 cerebrospinal fluid [CSF], synovial fluid, pericardial fluid, pleural fluid, or peritoneal

63 fluid).(Levine et al. 1999) The mortality rate associated with IPD is high, ranging from approximately 5.3 to $27.5 \%$, and identification of high-risk groups is important.(Berjohn et al. 2008; Chen et al. 2009; Gomez-Barreto et al. 2010; Marrie et al. 2011; Ruckinger et al. 2009; Rueda et al. 2010; Shariatzadeh et al. 2005; Ulloa-Gutierrez et al. 2003) Some factors associated with outcome include breastfeeding, passive smoking, antimicrobial resistance, pneumococcal serotype, and prompt use of antibiotics.(Berjohn et al. 2008; Haddad et al. 2008; Ruckinger et al. 2009; Tan 2012) The emerging resistance of $S$. pneumoniae brings challenges to successful treatment.(Ibrahim et al. 2000; Minami et al. 2015) The aim of this study was to survey the clinical manifestations and laboratory results of IPD in children and identify the prognostic 72 factors of mortality. 
77

78

79

80

81

82

83

84

85

\section{Study Design and Study Population}

This study was approved by the Ethics Committees of MacKay Memorial Hospital, Taiwan (IRB No.: 16MMHIS035e). MacKay Memorial Hospital is a tertiary teaching hospital in Taipei, Taiwan. From January 2001 to December 2006, a retrospective chart review of hospitalized pediatric patients were performed. Patients younger than 18 years old hospitalized for infectious etiologies, eg. pneumonia, meningitis, or sepsis, were enrolled in the study. Patients admitted for noninfectious causes were excluded, such as preterm delivery, diabetes mellitus, epilepsy, cardiovascular diseases, or scheduled chemotherapy. Since chronic underlying illness is a risk factor of IPD, patients with underlying diseases were not excluded in our analysis. The clinical history and laboratory tests were investigated to identify those with IPD. IPD is also a communicable disease in Taiwan and physicians have to report to Centers for Disease Control, Taiwan about patients with IPD. We also search the database of communicable diseases to detect patients with IPD. The electronic charts were also reviewed using the ICD-9-CM coding system to reduce missing patients with IPD. Only laboratory-confirmed cases were enrolled for investigation and analysis.

In total, 13,141 patients were admitted for infectious etiologies during the study period and enrolled in our screen. Among them, $50(0.4 \%)$ patients with pneumococcal infections proven by positive culture results or antigen tests were detected. Five patients $(10 \%)$ died and the clinical manifestations, laboratory data, and hospitalization courses were compared between the survival and mortality groups.

9 Laboratory Tests

Upon admission, blood tests including complete blood count, C-reactive protein (CRP) and 
101 blood cultures were routinely obtained. Spinal tap, pleurocentesis and video-assisted

102 thoracoscopic surgery were selectively performed according to the patients' clinical conditions

103 and the judgement of physicians. Data from blood, CSF, and pleural fluid cultures performed

104 using aseptic technique according to manufacturer's instructions were reviewed. Urine

105 pneumococcal antigen, a reliable tool with a moderate sensitivity and good specificity to detect

106 S. pneumoniae, was also investigated (Binax NOW S. pneumoniae urinary antigen test; Binax,

107 Portland, Maine).(Roson et al. 2004) Complete blood count, CRP, Thomsen-Friedenreich

108 antigen, and biochemistry results were also reviewed. Virus studies were also performed and

109 analyzed. Antibiotic susceptibility testing interpretation was based on Clinical and Laboratory

110 Standards Institute 2010 criteria.

111

112 Statistical Analysis

113 The statistical analysis was performed using SPSS version 15.0 (SPSS, Chicago, IL). Categorical

114 variables were compared using the chi-square test and Fisher's exact test. Continuous variables

115 were compared using the $\mathrm{t}$ test. Variables with a $p$-value $<0.05$ were included into multivariate

116 analysis. Log regression was performed for multivariate analysis. A $p$-value $<0.05$ was

117 considered statistically significant.

118

119

120 RESULTS

121

122 Of the 50 patients (median age, 3.5 years) included in the study, $30(60 \%)$ were males (Table 1$).$

123 Eight patients $(16 \%)$ had underlying diseases, such as leukemia or congenital heart disease. IPD 
124 was more common in cold seasons (36 patients, $72 \%$ in autumn and winter) and pneumonia was

125 diagnosed in 46 patients (92\%). Twenty-eight patients (56\%) had sepsis and four (8\%) had

126 meningitis. Three patients had concurrent involvement of pneumococcal meningitis, sepsis, and

127 pneumonia. Concurrent virus infection was noted in two patients (echovirus 6 and respiratory

128 syncytial virus, respectively) and both of them survived. Hemolytic uremic syndrome (HUS) was

129 observed in ten patients and extracorporeal membrane oxygenation (ECMO) was performed in

130 three patients. Leukocytosis and elevated levels of CRP and aspartate aminotransferase were

131 noted in most of the patients. Median hospital stay was 15 days and the overall mortality rate was $13210 \%$.

134 Comparing the clinical manifestations, laboratory data, and hospital course between the survival 135 and mortality groups, we found that leukopenia (white blood cell $<4,000 / \mu \mathrm{L}$ ), thrombocytopenia 136 (platelet count $<100,000 / \mu \mathrm{L})$, and high CRP levels (CRP $>20 \mathrm{mg} / \mathrm{dL})$ were significant

137 predictors for mortality (Table 2). Antibiotic resistance was not associated with mortality. The 138 multivariate analysis showed no significant single prognostic factor.

\section{DISCUSSION}

142 S. pneumoniae is the most important bacterial pathogen in both invasive and mucosal disease

143 worldwide.(Jroundi et al. 2014; O'Brien et al. 2009; Tan 2012; Wei et al. 2015) In 2000, it was

144 estimated to cause 14.5 million episodes of serious disease and $11 \%$ of all deaths in children

145 younger than 5 years.(O'Brien et al. 2009) The carrier rate is high and is influenced by a number

146 of factors, including age, race, exposure to cigarette smoke, and day care attendance.(Ebruke et 
147 al. 2015; Tan 2012) In a cross-sectional observational study conducted in the United Kingdom,

148 the carrier rate in children was 47\%.(Hamaluba et al. 2015) High prevalence of nasopharyngeal

149 carriage were also observed in many areas, such as Taiwan (21\%) and Egypt (29.2\%).(Chiou et

150 al. 1998; El-Nawawy et al. 2015)

151

152 Followed by the high prevalence of nasopharyngeal carriage, $S$. pneumoniae is the most common

153 pathogen in children with severe infection.(Jroundi et al. 2014) In hospitalized children with

154 acute respiratory infections, $S$. pneumoniae was the most frequently detected bacteria

155 (14.4\%).(Wei et al. 2015) In patients with IPD, the mortality rate is high in both children and

156 adults and the findings of some important studies are summarized in Table 3. Most of IPD

157 developed in young children and our study is consistent with previous report.(Prevention 2010)

158 Only 2 patients were older than 6 years old and both of them survived. Although the mortality

159 rate varies in different countries, time, and study, IPD remains an important health issue. Prompt

160 diagnosis and timely treatment are important. The burden of disease is heavy and S. pneumoniae

161 remains the most important health threat worldwide.

162

163 Pneumococcal pneumonia with empyema is the most common form of IPD. Infectious

164 endocarditis is a rare form of IPD, with a mortality rate 20.7\%.(de Egea et al. 2015) Most cases

165 of infectious endocarditis occur in adults with underlying disease; there were no children with

166 pneumococcal infectious endocarditis in our study group. The presence of pneumococcal

167 carriage and IPD is multifactorial. The presence of an underlying chronic illness is a risk factor,

168 whereas breastfeeding has protective effect against IPD.(Chen et al. 2009; Haddad et al. 2008;

169 Lee et al. 2003; Levine et al. 1999) Race and group child care attendance also play a role in

170 IPD.(Pilishvili et al. 2010) In patients with IPD, prompt and timely use of antibiotics is 
171 associated with favorable outcome; apparently, antimicrobial resistance does not affect

172 outcome.(Berjohn et al. 2008; Kumashi et al. 2005) The findings in our study are consistent with

173 those in previous reports. Upon admission, the presence of cytopenia and meningitis may

174 indicate unfavorable outcome.(Chen et al. 2009) In addition, we found thrombocytopenia and

175 high CRP levels to be associated with mortality. ECMO use and the presence of meningitis were

176 indicative of more severe disease and were associated with poor outcome. The presence of HUS

177 was not suggestive of poor prognosis in our study. Increased resistance of S. pneumoniae has

178 been reported and prompt and adequate antimicrobial treatment is essential for successful

179 treatment.(Ibrahim et al. 2000; Minami et al. 2015) For patients with suspected IPD, bacterial

180 cultures are the gold standard and provide tailored guidance to antibiotics use. It is important to

181 obtain specimens before initiating antimicrobial agents. However, cultures are time-consuming

182 and adequate empirical antibiotics regimen remains a challenge for primary physicians. Based on

183 the finding of our study, we suggest an aggressive antibiotic treatment and early surgical

184 intervention if needed in patients with leukopenia, thrombocytopenia and elevated CRP level at 185 admission.

187 The host immune responses to infections are regulated by a mixture of pro-inflammatory and 188 anti-inflammatory mediators. In addition to traditionally laboratory tests, genes encoding these 189 mediators are associated with disease progression and outcomes of patients with sepsis and are 190 regarded as a prognostic factor of severe infection. As medicine advances, mounting evidences 191 show that patient-specific genetic polymorphism contributes to disease prognosis and potential

192 for treatment.(Holmes et al. 2003) Various single nucleotide polymorphisms of genes that

193 encode cytokines, cell surface receptors, lipopolysaccharide ligands, mannose-binding lectin,

194 heat shock protein 70, angiotensin I-converting enzyme, plasminogen activator inhibitor, and 
195 caspase-12 are associated with increased susceptibility to infection and poor outcomes.(Frantz et

196 al. 2007) For example, programmed cell death 1 protein (PD-1) is a negative costimulatory

197 molecule and involved in the host responses to sepsis. Patients with G homozygotes of PD-1

198 rs11568821 had higher risk of mortality, sepsis score and a higher demand of vasopressor

199 therapy than A allele carriers.(Mansur et al. 2014) Similarly, CD14 plays a crucial role in

200 initiating and perpetuating the pro-inflammatory processes during sepsis. Compared with the C-

201 allele carrier of CD14 rs2569190, TT-homozygous patients had a favorable outcome in

202 sepsis.(Mansur et al. 2015) The importance of genetic polymorphism and infectious disease

203 warrants our attention. Association between genetic polymorphisms and IPD is also

204 reported.(Brouwer et al. 2009; Lundbo et al. 2016; Rautanen et al. 2016) For instance, in Kenya

205 children, polymorphism in a lincRNA was associated with a doubled risk of pneumococcal

206 bacteremia.(Rautanen et al. 2016) Genetic counselling was performed in our study patients but

207 genetic susceptibilities were not tested. Further studies are warranted to elucidate the relationship

208 between genetic polymorphism and IPD and genetic polymorphism may serve as a valuable

209 prognostic factor in patients with IPD.

210

211 Our study has some limitations. First, the sample size was too small that the multivariate analysis

212 showed no significant single prognostic factor. IPD is a severe and relatively rare disease and the

213 estimated incidence of IPD was approximate 12.9/100,000.(Prevention 2010) Our study

214 demonstrated three prognostic factors of unfavorable outcome of IPD, but no statistically

215 significant prognostic factor was identified in multivariate analysis due to relatively small sample

216 size. Further large-scale, prospective studies are warranted. Second, the pneumococcal serotype

217 was not investigated. Association between pneumococcal serotypes and patient outcomes has

218 been reported.(Ciruela et al. 2013; Kapatai et al. 2016; Ruckinger et al. 2009; Weinberger et al. 
219 2010) However, serotype identification is not always available in most hospitals and, therefore,

220 its clinical use is limited. Furthermore, our study was conducted before the introduction of

221 pneumococcal conjugate vaccination in Taiwan and the protective effects of pneumococcal

222 vaccination were not investigated. The introduction of pneumococcal conjugate vaccination has

223 dramatically decreased the incidence of IPD.(2010; Abdelnour et al. 2015; Pilishvili et al. 2010;

224 von Gottberg et al. 2014) In the era of post-heptavalent pneumococcal conjugate vaccine,

225 serotype replacement and breakthrough infection are of global concern.(Abdelnour et al. 2015;

226 Park et al. 2010; Tan 2012) The vaccine coverage rate differs among different countries; for

227 example, the coverage rate is approximately $90 \%$ in the United States and $10 \%$ in Shanghai,

228 China.(Boulton et al. 2016; Hill et al. 2015) Therefore, the protective effect of vaccination is

229 influenced by the coverage rate and is difficult to evaluate. Finally, this study is a retrospective

230 study and conducted in one teaching hospital in northern Taiwan. Some tests were not always

231 available and there were some missing data. For example, spinal tap and pleurocentesis were not

232 performed in all patients. The prevalence, managements, outcomes and findings may be different

233 in different hospitals, areas, countries and eras.

234

235 In conclusion, S. pneumoniae remains an important health threat worldwide, and IPD is a life-

236 threatening disease with a high mortality rate. Pneumococcal vaccination should be encouraged

237 and physicians should maintain high alertness toward patients with IPD. We found leukopenia,

238 thrombocytopenia, and high CRP levels to be associated with mortality in pediatric IPD, and

239 these factors are worthy of special attention at admission. Although we failed to identify a

240 statistically significant prognostic factor in multivariate analysis due to relatively small sample

241 size, we suggest an aggressive antibiotic treatment in patients with these factors at admission.

242 Further large-scale studies are warranted. 


\section{REFERENCES}

246

247

248

249

250

251

252

253

254

255

256

257

258

259

260

261

262

263

264

265

266

267

268

269

270

271

272

273

274

275

276

277

2010. Invasive pneumococcal disease in young children before licensure of 13 -valent pneumococcal conjugate vaccine - United States, 2007. MMWR Morb Mortal Wkly Rep 59:253-257.

Abdelnour A, Arguedas A, Dagan R, Soley C, Porat N, Mercedes Castrejon M, Ortega-Barria E, Colindres R, Pirçon J-Y, DeAntonio R, and Van Dyke MK. 2015. Etiology and Antimicrobial Susceptibility of Middle Ear Fluid Pathogens in Costa Rican Children With Otitis Media Before and After the Introduction of the 7-Valent Pneumococcal Conjugate Vaccine in the National Immunization Program: Acute otitis media microbiology in Costa Rican children. Medicine 94:e320. 10.1097/md.0000000000000320

Berjohn CM, Fishman NO, Joffe MM, Edelstein PH, and Metlay JP. 2008. Treatment and Outcomes for Patients With Bacteremic Pneumococcal Pneumonia. Medicine 87:160166. 10.1097/MD.0b013e318178923a

Boulton ML, Ravi NS, Sun X, Huang Z, and Wagner AL. 2016. Trends in childhood pneumococcal vaccine coverage in Shanghai, China, 2005-2011: a retrospective cohort study. BMC Public Health 16:109. 10.1186/s12889-016-2785-7

Brouwer MC, de Gans J, Heckenberg SG, Zwinderman AH, van der Poll T, and van de Beek D. 2009. Host genetic susceptibility to pneumococcal and meningococcal disease: a systematic review and meta-analysis. Lancet Infect Dis 9:31-44. 10.1016/s14733099(08)70261-5

Chen CJ, Lin CL, Chen YC, Wang CW, Chiu CH, Lin TY, and Huang YC. 2009. Host and microbiologic factors associated with mortality in Taiwanese children with invasive pneumococcal diseases, 2001 to 2006. Diagn Microbiol Infect Dis 63:194-200. S07328893(08)00437-9 [pii]

10.1016/j.diagmicrobio.2008.10.006

Chiou CC, Liu YC, Huang TS, Hwang WK, Wang JH, Lin HH, Yen MY, and Hsieh KS. 1998. Extremely high prevalence of nasopharyngeal carriage of penicillin-resistant Streptococcus pneumoniae among children in Kaohsiung, Taiwan. J Clin Microbiol 36:1933-1937.

Ciruela P, Soldevila N, Selva L, Hernández S, Garcia-Garcia JJ, Moraga F, de Sevilla MF, Codina G, Planes AM, Esteva C, Coll F, Cardeñosa N, Jordan I, Batalla J, Salleras L, 
278

279

280

281

282

283

284

285

286

287

288

289

290

291

292

293

294

295

296

297

298

299

300

301

302

303

304

305

306

307

308

309

310

311

312

313

Muñoz-Almagro C, and Domínguez A. 2013. Are risk factors associated with invasive pneumococcal disease according to different serotypes? Human Vaccines \& Immunotherapeutics 9:712-719. 10.4161/hv.23270

de Egea V, Muñoz P, Valerio M, de Alarcón A, Lepe JA, Miró JM, Gálvez-Acebal J, GarcíaPavía P, Navas E, Goenaga MA, Fariñas MC, Vázquez EG, Marín M, Bouza E, and Group atGS. 2015. Characteristics and Outcome of Streptococcus pneumoniae Endocarditis in the XXI Century: A Systematic Review of 111 Cases (2000-2013). Medicine 94:e1562. 10.1097/md.0000000000001562

Ebruke C, Roca A, Egere U, Darboe O, Hill PC, Greenwood B, Wren BW, Adegbola RA, and Antonio M. 2015. Temporal changes in nasopharyngeal carriage of Streptococcus pneumoniae serotype 1 genotypes in healthy Gambians before and after the 7-valent pneumococcal conjugate vaccine. PeerJ 3:e903. 10.7717/peerj.903

El-Nawawy AA, Hafez SF, Meheissen MA, Shahtout NM, and Mohammed EE. 2015. Nasopharyngeal Carriage, Capsular and Molecular Serotyping and Antimicrobial Susceptibility of Streptococcus pneumoniae among Asymptomatic Healthy Children in Egypt. Journal of Tropical Pediatrics 61:455-463. 10.1093/tropej/fmv060

Frantz S, Ertl G, and Bauersachs J. 2007. Mechanisms of disease: Toll-like receptors in cardiovascular disease. Nat Clin Pract Cardiovasc Med 4:444-454. 10.1038/ncpcardio0938

Gomez-Barreto D, Espinosa-Monteros LE, Lopez-Enriquez C, Jimenez-Rojas V, and RodriguezSuarez R. 2010. Invasive pneumococcal disease in a third level pediatric hospital in Mexico City: epidemiology and mortality risk factors. Salud Publica Mex 52:391-397.

Haddad MB, Porucznik CA, Joyce KE, De AK, Pavia AT, Rolfs RT, and Byington CL. 2008. Risk factors for pediatric invasive pneumococcal disease in the Intermountain West, 1996-2002. Ann Epidemiol 18:139-146. 10.1016/j.annepidem.2007.09.006

Hamaluba M, Kandasamy R, Ndimah S, Morton R, Caccamo M, Robinson H, Kelly S, Field A, Norman L, Plested E, Thompson BAV, Zafar A, Kerridge SA, Lazarus R, John T, Holmes J, Fenlon SN, Gould KA, Waight P, Hinds J, Crook D, Snape MD, and Pollard AJ. 2015. A Cross-Sectional Observational Study of Pneumococcal Carriage in Children, Their Parents, and Older Adults Following the Introduction of the 7-Valent Pneumococcal Conjugate Vaccine. Medicine 94:e335. 10.1097/md.0000000000000335 Hill HA, Elam-Evans LD, Yankey D, Singleton JA, and Kolasa M. 2015. National, State, and Selected Local Area Vaccination Coverage Among Children Aged 19-35 Months United States, 2014. MMWR Morb Mortal Wkly Rep 64:889-896.

Holmes CL, Russell JA, and Walley KR. 2003. Genetic polymorphisms in sepsis and septic shock: role in prognosis and potential for therapy. Chest 124:1103-1115. 
314 Ibrahim EH, Sherman G, Ward S, Fraser VJ, and Kollef MH. 2000. The influence of inadequate

315

316

317

318

319

320

321

322

323

324

325

326

327

328

329

330

331

332

333

334

335

336

337

338

339

340

341

342

343

344

345

346

347

348

349

antimicrobial treatment of bloodstream infections on patient outcomes in the ICU setting. Chest 118:146-155.

Jroundi I, Mahraoui C, Benmessaoud R, Moraleda C, Tligui H, Seffar M, Kettani SC, Benjelloun BS, Chaacho S, Maaroufi A, Hayes EB, Álvarez-Martínez MJ, Muñoz-Almagro C, Ruiz J, Alonso PL, and Bassat Q. 2014. The Epidemiology and Aetiology of Infections in Children Admitted with Clinical Severe Pneumonia to a University Hospital in Rabat, Morocco. Journal of Tropical Pediatrics 60:270-278. 10.1093/tropej/fmu010

Kapatai G, Sheppard CL, Al-Shahib A, Litt DJ, Underwood AP, Harrison TG, and Fry NK. 2016. Whole genome sequencing of Streptococcus pneumoniae: development, evaluation and verification of targets for serogroup and serotype prediction using an automated pipeline. PeerJ 4:e2477. 10.7717/peerj.2477

Kumashi P, Girgawy E, Tarrand JJ, Rolston KV, Raad II, and Safdar A. 2005. Streptococcus pneumoniae Bacteremia in Patients With Cancer: Disease Characteristics and Outcomes in the Era of Escalating Drug Resistance (1998-2002). Medicine 84:303-312.

Lee CY, Chiu CH, Huang YC, Chung PW, Su LH, Wu TL, and Lin TY. 2003. Invasive pneumococcal infections: a clinical and microbiological analysis of 53 patients in Taiwan. Clin Microbiol Infect 9:614-618.

Levine OS, Farley M, Harrison LH, Lefkowitz L, McGeer A, and Schwartz B. 1999. Risk factors for invasive pneumococcal disease in children: a population-based case-control study in North America. Pediatrics 103:E28.

Lundbo LF, Harboe ZB, Clausen LN, Hollegaard MV, Sorensen HT, Hougaard DM, Konradsen HB, Norgaard M, and Benfield T. 2016. Genetic Variation in NFKBIE Is Associated With Increased Risk of Pneumococcal Meningitis in Children. EBioMedicine 3:93-99. 10.1016/j.ebiom.2015.11.048

Mansur A, Hinz J, Hillebrecht B, Bergmann I, Popov AF, Ghadimi M, Bauer M, Beissbarth T, and Mihm S. 2014. Ninety-day survival rate of patients with sepsis relates to programmed cell death 1 genetic polymorphism rs11568821. J Investig Med 62:638-643. 10.2310/jim.0000000000000059

Mansur A, Liese B, Steinau M, Ghadimi M, Bergmann I, Tzvetkov M, Popov AF, Beissbarth T, Bauer M, and Hinz J. 2015. The CD14 rs2569190 TT Genotype Is Associated with an Improved 30-Day Survival in Patients with Sepsis: A Prospective Observational Cohort Study. PLoS ONE 10:e0127761. 10.1371/journal.pone.0127761

Marrie TJ, Tyrrell GJ, Garg S, and Vanderkooi OG. 2011. Factors Predicting Mortality in Invasive Pneumococcal Disease in Adults in Alberta. Medicine 90:171-179. 10.1097/MD.0b013e31821a5a76 
350

351

352

353

354

355

356

357

358

359

360

361

362

363

364

365

366

367

368

369

370

371

372

373

374

375

376

377

378

379

380

381

382

383

384

385

Minami M, Sakakibara R, Imura T, Morita H, Kanemaki N, and Ohta M. 2015. Antimicrobial susceptibility patterns of multi-drug resistant Streptococcus pneumoniae at general hospital in Japan. J Microbiol Immunol Infect 48:S65-S66. 10.1016/j.jmii.2015.02.229

O'Brien KL, Wolfson LJ, Watt JP, Henkle E, Deloria-Knoll M, McCall N, Lee E, Mulholland K, Levine OS, and Cherian T. 2009. Burden of disease caused by Streptococcus pneumoniae in children younger than 5 years: global estimates. Lancet 374:893-902. 10.1016/s01406736(09)61204-6

Park SY, Van Beneden CA, Pilishvili T, Martin M, Facklam RR, and Whitney CG. 2010. Invasive pneumococcal infections among vaccinated children in the United States. $J$ Pediatr 156:478-483.e472. 10.1016/j.jpeds.2009.10.008

Pilishvili T, Zell ER, Farley MM, Schaffner W, Lynfield R, Nyquist AC, Vazquez M, Bennett NM, Reingold A, Thomas A, Jackson D, Schuchat A, and Whitney CG. 2010. Risk factors for invasive pneumococcal disease in children in the era of conjugate vaccine use. Pediatrics 126:e9-17. 10.1542/peds.2009-2150

Prevention CfDCa. 2010. Active Bacterial Core Surveillance (ABCs) report, Emerging Infections Program Network Streptococcus pneumoniae, 2010. http://wwwcdcgov/abcs/reports-findings/survreports/spneu10-origpdf.

Rautanen A, Pirinen M, Mills TC, Rockett KA, Strange A, Ndungu AW, Naranbhai V, Gilchrist JJ, Bellenguez C, Freeman C, Band G, Bumpstead SJ, Edkins S, Giannoulatou E, Gray E, Dronov S, Hunt SE, Langford C, Pearson RD, Su Z, Vukcevic D, Macharia AW, Uyoga S, Ndila C, Mturi N, Njuguna P, Mohammed S, Berkley JA, Mwangi I, Mwarumba S, Kitsao BS, Lowe BS, Morpeth SC, Khandwalla I, Blackwell JM, Bramon E, Brown MA, Casas JP, Corvin A, Duncanson A, Jankowski J, Markus HS, Mathew CG, Palmer CN, Plomin R, Sawcer SJ, Trembath RC, Viswanathan AC, Wood NW, Deloukas P, Peltonen L, Williams TN, Scott JA, Chapman SJ, Donnelly P, Hill AV, and Spencer CC. 2016. Polymorphism in a lincRNA Associates with a Doubled Risk of Pneumococcal Bacteremia in Kenyan Children. Am J Hum Genet 98:1092-1100. 10.1016/j.ajhg.2016.03.025

Roson B, Fernandez-Sabe N, Carratala J, Verdaguer R, Dorca J, Manresa F, and Gudiol F. 2004. Contribution of a urinary antigen assay (Binax NOW) to the early diagnosis of pneumococcal pneumonia. Clin Infect Dis 38:222-226. 10.1086/380639

Ruckinger S, von Kries R, Siedler A, and van der Linden M. 2009. Association of serotype of Streptococcus pneumoniae with risk of severe and fatal outcome. Pediatr Infect Dis $J$ 28:118-122. 10.1097/INF.0b013e318187e215

Rueda AM, Serpa JA, Matloobi M, Mushtaq M, and Musher DM. 2010. The Spectrum of Invasive Pneumococcal Disease at an Adult Tertiary Care Hospital in the Early 21st 
386

387

388

389

390

391

392

393

394

395

396

397

398

399

400

401

402

403

404

405

406

407

Century. Medicine 89:331-336. 10.1097/MD.0b013e3181f2b824

Shariatzadeh MR, Huang JQ, Tyrrell GJ, Johnson MM, and Marrie TJ. 2005. Bacteremic

Pneumococcal Pneumonia: A Prospective Study in Edmonton and Neighboring Municipalities. Medicine 84:147-161.

Tan TQ. 2012. Pediatric invasive pneumococcal disease in the United States in the era of pneumococcal conjugate vaccines. Clin Microbiol Rev 25:409-419. 10.1128/cmr.0001812

Ulloa-Gutierrez R, Avila-Aguero ML, Herrera ML, Herrera JF, and Arguedas A. 2003. Invasive pneumococcal disease in Costa Rican children: a seven year survey. Pediatr Infect Dis $J$ 22:1069-1074. 10.1097/01.inf.0000101475.45195.b1

von Gottberg A, de Gouveia L, Tempia S, Quan V, Meiring S, von Mollendorf C, Madhi SA, Zell ER, Verani JR, O’Brien KL, Whitney CG, Klugman KP, and Cohen C. 2014. Effects of Vaccination on Invasive Pneumococcal Disease in South Africa. New England Journal of Medicine 371:1889-1899. doi:10.1056/NEJMoa1401914

Wei L, Liu W, Zhang X-A, Liu E-M, Wo Y, Cowling BJ, and Cao W-C. 2015. Detection of Viral and Bacterial Pathogens in Hospitalized Children With Acute Respiratory Illnesses, Chongqing, 2009-2013. Medicine 94:e742. 10.1097/md.0000000000000742

Weinberger DM, Harboe ZB, Sanders EA, Ndiritu M, Klugman KP, Ruckinger S, Dagan R, Adegbola R, Cutts F, Johnson HL, O'Brien KL, Scott JA, and Lipsitch M. 2010. Association of serotype with risk of death due to pneumococcal pneumonia: a metaanalysis. Clin Infect Dis 51:692-699. 10.1086/655828 


\section{Table 1 (on next page)}

Table 1

Clinical manifestations of patients with IPD 
1 Table 1 Clinical manifestations of patients with IPD

\begin{tabular}{|c|c|c|c|c|}
\hline & $\begin{array}{l}\text { Overall } \\
(n=50)\end{array}$ & $\begin{array}{l}\text { Survival } \\
(n=45)\end{array}$ & $\begin{array}{l}\text { Mortality } \\
(n=5)\end{array}$ & $p$-value \\
\hline Age, y & $3.5 \pm 0.82$ & $3.6 \pm 0.92$ & $2.7 \pm 1.5$ & 0.083 \\
\hline Male, n (\%) & $30(60)$ & $26(57.8)$ & $4(80)$ & 0.63 \\
\hline Cold seasons, n (\%) & $36(72)$ & $34(75.6)$ & $2(40)$ & 0.248 \\
\hline $\begin{array}{l}\text { Underlying disease, } \\
\text { n (\%) }\end{array}$ & $8(16)$ & $7(15.6)$ & $1(20)$ & 0.70 \\
\hline \multicolumn{5}{|l|}{ Involved organ } \\
\hline Lung, n (\%) & $46(92)$ & $42(93.3)$ & $4(80)$ & 0.862 \\
\hline Blood, n (\%) & $28(56)$ & $27(60)$ & $1(20)$ & 0.217 \\
\hline CNS, n (\%) & $4(8)$ & $2(4.4)$ & $2(40)$ & 0.056 \\
\hline Hospital days, d & 14.56 & $15 \pm 2.76$ & 10.2 & \\
\hline ECMO use, n (\%) & $3(6)$ & $1(2.2)$ & $2(40)$ & $0.017^{*}$ \\
\hline HUS, n (\%) & $10(20)$ & $9(20)$ & $1(20)$ & 0.72 \\
\hline \multicolumn{5}{|l|}{ Laboratory tests } \\
\hline $\mathrm{Hb}, \mathrm{g} / \mathrm{dl}$ & $11.37 \pm 0.48$ & $11.92 \pm 2.03$ & $11.3 \pm 0.5$ & 0.441 \\
\hline $\mathrm{WBC}, / \mu \mathrm{L}$ & $\begin{array}{l}16004 \pm \\
2861\end{array}$ & $16824 \pm 2966$ & $\begin{array}{l}8624 \pm \\
5227\end{array}$ & 0.084 \\
\hline Platelet, $/ \mu \mathrm{L}$ & $311.8 \pm 54.9$ & $322.7 \pm 56.7$ & $\begin{array}{l}215.6 \pm \\
283.5\end{array}$ & 0.239 \\
\hline CRP, mg/dl & $17.95 \pm 4.28$ & $16.63 \pm 4.61$ & $\begin{array}{l}29.06 \pm \\
6.99\end{array}$ & 0.071 \\
\hline AST, IU/L & $\begin{array}{l}70.25 \pm \\
29.23\end{array}$ & $62.26 \pm 31.5$ & $\begin{array}{l}100.6 \pm \\
102.94\end{array}$ & 0.28 \\
\hline Creatinine, $\mathrm{mg} / \mathrm{dl}$ & $0.86 \pm 0.28$ & $0.9 \pm 0.36$ & $0.74 \pm 0.45$ & 0.667 \\
\hline $\mathrm{Na}, \mathrm{meq} / \mathrm{L}$ & $135.3 \pm 1.6$ & $135.5 \pm 1.7$ & $134.4 \pm 5.9$ & 0.599 \\
\hline $\begin{array}{l}\text { Resistant to } \\
\text { Penicillin }\end{array}$ & $16(37.2)$ & $15(37.5)$ & $1(33)$ & 0.63 \\
\hline
\end{tabular}

2 For categorical variables, the results are expressed as number (percentage); for continuous

3 variables, the results are expressed as mean \pm standard deviation. A $p$-value less than 0.05 is 4 considered statistically significant and indicated by an asterisk (*). 


\section{Table 2 (on next page)}

Table 2

Prognostic factors of patients with IPD 
1 Table 2 Prognostic factors of patients with IPD

\begin{tabular}{|c|c|c|c|c|}
\hline & $\begin{array}{l}\text { Overall } \\
(n=50)\end{array}$ & $\begin{array}{c}\text { Survival } \\
(n=45)\end{array}$ & $\begin{array}{l}\text { Mortality } \\
\qquad(n=5)\end{array}$ & $p$-value \\
\hline Age $\leq 2$ y & $17(34)$ & $15(33.3)$ & $2(40)$ & 0.842 \\
\hline $\mathrm{Hb} \leq 10 \mathrm{~g} / \mathrm{dL}$ & $9(18)$ & $8(17.8)$ & $1(20)$ & 0.624 \\
\hline$W B C \leq 4,000 / \mu \mathrm{L}$ & $7(14)$ & $4(8.9)$ & $3(60)$ & $0.015^{*}$ \\
\hline$W B C \geq 20,000 / \mu L$ & $15(30)$ & $14(31.1)$ & $1(20)$ & 1.00 \\
\hline Plt $\leq 100,000 / \mu \mathrm{L}$ & $7(14)$ & $4(8.9)$ & $3(60)$ & $0.014^{*}$ \\
\hline $\mathrm{CRP} \geq 20 \mathrm{mg} / \mathrm{dL}$ & $22(44)$ & $17(37.8)$ & $5(100)$ & $0.029 *$ \\
\hline Meningitis n (\%) & $4(8)$ & $2(4.4)$ & $2(40)$ & 0.056 \\
\hline ECMO use, n (\%) & $3(6)$ & $1(2.2)$ & $2(40)$ & $0.017 *$ \\
\hline
\end{tabular}

2 For categorical variables, the results are expressed as number (percentage); for continuous

3 variables, the results are expressed as mean \pm standard deviation. A $p$-value less than 0.05 is 4 considered statistically significant and indicated by an asterisk (*).

5

6 


\section{Table $\mathbf{3}$ (on next page)}

Table 3

Reported mortality in patients with IPD 
1 Table 3 Reported mortality in patients with IPD

\begin{tabular}{|c|c|c|c|c|c|c|c|c|c|}
\hline Authors & Ulloa-Gutierrez & Ruckinger & Gomez-Barreto & Shariatzadeh & Marrie & Rueda & Berjohn & Chen & $\begin{array}{l}\text { Current } \\
\text { study }\end{array}$ \\
\hline Age & Children & Children & Children & Adults & Adults & Adults & Adults & Children & Children \\
\hline $\begin{array}{l}\text { Study } \\
\text { period }\end{array}$ & $1995-2001$ & $1997-2003$ & $1997-2004$ & $2000-2002$ & $2000-2004$ & $2000-2008$ & 2001-2004 & 2001-2006 & 2001-2006 \\
\hline Country & Costa Rica & Germany & Mexico & Canada & Canada & $\begin{array}{l}\text { United } \\
\text { States }\end{array}$ & $\begin{array}{l}\text { United } \\
\text { States }\end{array}$ & Taiwan & Taiwan \\
\hline IPD & All IPD & All IPD & All IPD & $\begin{array}{l}\text { Pneumonia, } \\
\text { bacteremia }\end{array}$ & All IPD & All IPD & $\begin{array}{l}\text { Pneumonia, } \\
\text { bacteremia }\end{array}$ & All IPD & All IPD \\
\hline $\begin{array}{l}\text { Mortality } \\
\text { (\%) }\end{array}$ & 14.4 & 5.3 & 27.5 & 9.3 & 14.1 & 16.2 & 10 & 8.1 & 10 \\
\hline
\end{tabular}

